\title{
Hiding in plain sight — relapsing polychondritis disguised as uncontrolled asthma
}

\author{
Nico De Crem, Sofie Happaerts, Lieven J Dupont \\ Department of Respiratory Diseases, University Hospitals Leuven, Leuven, Belgium
}

A 55-year-old man was evaluated at the emergency department because of increasing shortness of breath and cough. His medical history included pulmonary embolism and asthma for 9 years which was uncontrolled despite montelukast, omalizumab and inhaled fluticasone, vilanterol and beclomethasone. Recent treatment with methylprednisolone and amoxicillin and clavulanic acid did not sufficiently alleviate his symptoms.

On presentation the patient appeared mildly ill. Blood pressure was 137/84 mm Hg, pulse 104/min, temperature $37.7^{\circ} \mathrm{C}$ and oxygen saturation $95 \%$ while breathing ambient air. On auscultation inspiratory wheezing was heard. Clinical examination was otherwise normal including external inspection of nose and ears. Blood analysis showed elevated inflammatory markers (C-reactive protein [CRP] $129.1 \mathrm{mg} / \mathrm{L}$ ) with a normal white blood cell count. His last spirometry from one month prior showed severe obstruction (forced expiratory volume in one second to forced vital capacity $\left[\mathrm{FEV}_{1} / \mathrm{FVC}\right] 43 \%$ and $\mathrm{FEV}_{1} 1.57 \mathrm{~L}$ or $35 \%$ predicted) with no reversibility after inhalation of salbutamol.

Contrast-enhanced computed tomography (CT) of the chest demonstrated remarkable thickening and calcification of the tracheobronchial walls with sparing of the posterior tracheal wall (Figure 1A and 1B). Bronchoscopy revealed tracheobronchomalacia (TBM) and thickened tracheal mucosa with a cobblestone appearance (Figure 1C and 1D). Tracheal biopsies showed non-specific chronic inflammation without granulomas. Congo red staining was negative. On additional fluorodeoxyglucose (FDG)-positron emission tomography (PET) hypercaptation of the nasal and costal cartilage and the thickened tracheal and bronchial walls (Figure $1 \mathrm{E}$ and $\mathrm{F}$ ) was seen. Further elaborate auto-immune screening was negative. A diagnosis of relapsing polychondritis was made.

Relapsing polychondritis is a rare auto-immune disorder characterized by recurrent episodes of cartilaginous inflammation throughout the body, especially in the ears, nose, eyes, respiratory tract and joints. Annual incidence ranges from 0.71 to 3,5 cases per million persons [1,2]. Men and women are equally affected with symptom onset usually between the fifth and seventh decade.

The most common and striking feature is auricular chondritis, present in $43 \%$ of patients at disease onset and in 89\% throughout disease course [2]. Typically, pain, tenderness and an erythematous appearance of the ear with sparing of the ear lobes is present. Involvement of the respiratory tract, however, is often underrecognized and underreported, although laryngotracheal disease occurs in 55\% of patients [3]. The most common symptoms are dyspnea, cough, stridor and hoarsesness [4]. Often symptoms are mistaken for other conditions and diagnosis is delayed. CT shows TBM and/or tracheobronchial wall thickening, with sparing of the posterior wall and with or without calcifications, in more than 50\% [4]. Other possible respiratory tract complications include subglottic and tracheal/tracheobronchial stenoses.

Diagnosis is based on a high level of suspicion and diagnostic criteria, such as the McAdam and Modified Damiana criteria [5, 6]. Need for biopsy of affected cartilage depends on these criteria and is not routinely recommended. Since laryngotracheal involvement is associated with a poor prognosis, prompt appropriate treatment with high dose corticosteroids and cyclophosphamide is recommended [7]. Our patient was started on corticosteroids and cyclophosphamide orally with a slow but steady improvement of symptoms and continues to do well. The most recent $\mathrm{FEV}_{1}$ was $52 \%$ predicted.

Address for correspondence: Nico De Crem, Department of Respiratory Diseases, University Hospitals Leuven, Leuven, Belgium; e-mail: nico.decrem@uzleuven.be Conflict of interest: None declared.

DOI: 10.5603/ARM.a2021.0064 | Received: 13.06.2021 | Copyright (C 2021 PTChP | ISSN 2451-4934 | e-ISSN 2543-6031

This article is available in open access under Creative Common Attribution-Non-Commercial-No Derivatives 4.0 International (CC BY-NC-ND 4.0) license, allowing to download articles and share them with others as long as they credit the authors and the publisher, but without permission to change them in any way or use them commercially. 

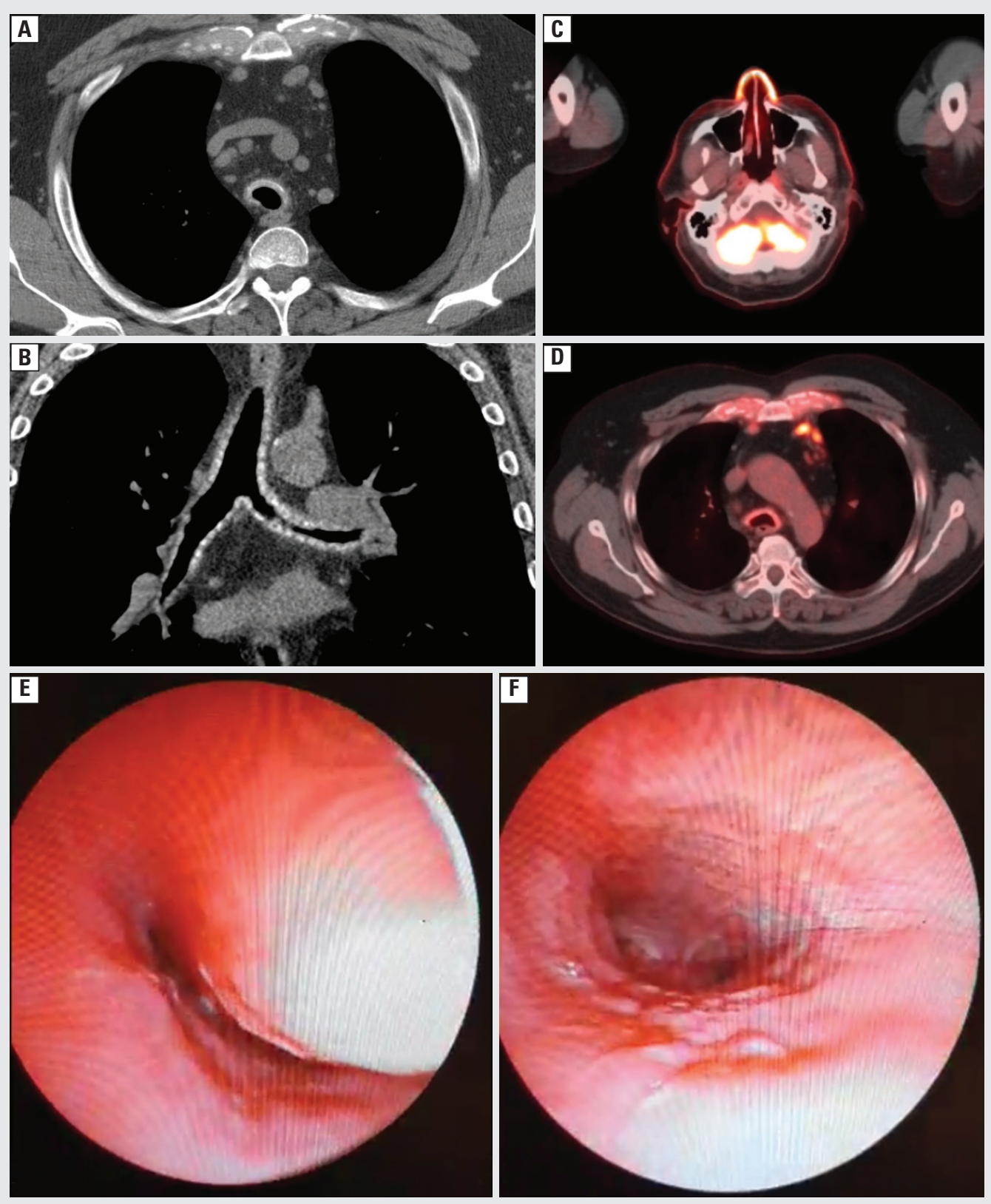

Figure 1. Chest computed tomography showing thickening and calcification of tracheal $(\mathbf{A})$ and bronchial cartilage (B). Positron emission tomographyshowing fluorodeoxyglucose (FDG) captation of the nasal cartilage (C) and FDG captation of costal and tracheal cartilage (D). Bronchoscopy revealing tracheobronchomalacia $(\mathbf{E})$ and thickened tracheal mucosa with cobblestone appearance $(\mathbf{F})$

\section{References:}

1. Hazra N, Dregan A, Charlton J, et al. Incidence and mortality of relapsing polychondritis in the UK: a population-based cohort study. Rheumatology (Oxford). 2015; 54(12): 2181-2187, doi: 10.1093/rheumatology/kev240, indexed in Pubmed: 26187053.

2. Kent PD, Michet CJ, Luthra HS. Relapsing polychondritis. Curr Opin Rheumatol. 2004; 16(1): 56-61, doi: 10.1097/00002281200401000-00011, indexed in Pubmed: 14673390.

3. Rafeq S, Trentham D, Ernst A. Pulmonary manifestations of relapsing polychondritis. Clin Chest Med. 2010; 31(3): 513-518, doi: 10.1016/j.ccm.2010.04.004, indexed in Pubmed: 20692543.

4. Ernst A, Rafeq S, Boiselle P, et al. Relapsing polychondritis and airway involvement. Chest. 2009; 135(4): 1024-1030, doi: 10.1378/ chest.08-1180, indexed in Pubmed: 19017885.

5. McAdam L, O Hanlan M, Bluestone R, et al. Relapsing polychondritis. Medicine. 1976; 55(3): 193-215, doi: 10.1097/00005792197605000-00001.

6. Damiani JM, Levine HL. Relapsing polychondritis — report of ten cases. Laryngoscope. 1979; 89(6 Pt 1): 929-946, indexed in Pubmed: $\underline{449538}$.

7. Ruhlen JL, Huston KA, Wood WG. Relapsing polychondritis with glomerulonephritis. Improvement with prednisone and cyclophosphamide. JAMA. 1981; 245(8): 847-848, indexed in Pubmed: $\underline{763678 .}$ 